\title{
BMJ Global Health Implementing essential interventions for cardiovascular disease risk management in primary healthcare: lessons from Eastern Europe and Central Asia
}

\author{
Dylan Collins (D) , ${ }^{1}$ Tiina Laatikainen, ${ }^{2,3}$ Jill Farrington ${ }^{4}$
}

\begin{abstract}
To cite: Collins D, Laatikainen T, Farrington J. Implementing essential interventions for cardiovascular disease risk management in primary healthcare: lessons from Eastern Europe and Central Asia. BMJ Global Health 2020;5:e002111. doi:10.1136/ bmjgh-2019-002111
\end{abstract}

Handling editor Seye Abimbola

Received 24 October 2019 Revised 12 January 2020 Accepted 13 January 2020

Check for updates

C) Author(s) (or their employer(s)) 2020. Re-use permitted under CC BY-NC. No commercial re-use. See rights and permissions. Published by BMJ.

${ }^{1}$ The University of British Columbia, Vancouver, British Columbia, Canada

${ }^{2}$ Institute of Public Health and Clinical Nutrition, University of Eastern Finland, Joensuu, Finland

${ }^{3}$ National Institute for Health and Welfare, Helsinki, Uusimaa, Finland

${ }^{4}$ World Health Organization Regional Office for Europe, Copenhagen, Denmark

Correspondence to Dr Dylan Collins;

dylan.collins@alumni.ubc.ca

\section{ABSTRACT}

Globally, non-communicable diseases (NCDs) are the leading cause of morbidity and mortality, including in the WHO European region. Within this region, the Member States with the greatest cardiovascular disease (CVD) burden are also some of the lowest resourced. As the need for technical support for the implementation of essential CVD/NCD interventions in primary healthcare (PHC) in these regions grew urgent, the WHO Regional Office for Europe has been directly supporting national governments in the development, assessment, scale-up and quality improvement of large scale PHC interventions for CVD. Herein, we synthesise the key learnings from providing technical support to national governments under the auspices of the WHO across the European region and share these learnings as a resource for public health professionals to consider when increasing coverage of quality essential health services. Based on our experience providing technical support to a diversity of Member States in the European Region (eg, Tajikistan, Republic of Moldova Ukraine and Uzbekistan), we have identified six key lessons: prioritising NCDs for public health intervention, identifying and mapping existing resources, engaging key stakeholders, tailoring interventions to the local health system, generating local evidence and ensuring quality improvement while mainstreaming. Common challenges across all phases of implementation include multiple and inconsistent international toolkits and guidance, lack of national capacity for evidence-based healthcare, limited access to essential medicines and technologies, inconsistent national guidelines and limited experience in evaluation methodology, clinical epidemiology and guideline implementation. We map the lessons to the Consolidated Framework for Implementation Research and highlight key learnings and challenges specific to the region. Member States in the region are at various stages of implementation; however, several are currently conducting pragmatic clinical trials to generate local evidence for health policy. As this work expands, greater engagement with peer-to-peer sharing of contextual wisdom, sharing of resources, publishing methodology and results and development of region-specific resources is planned.
Summary box

- This Practice article is intended for those involved in the implementation of primary healthcare interventions for the prevention and management of cardiovascular disease risk in settings with a high disease burden and limited resources.

- Working under the auspices of the WHO Regiona Office for Europe to support Member States at a national level, we synthesise our six key learnings from a breadth of projects and settings from Eastern Europe and Central Asia.

- We map these lessons to the Consolidated Framework for Implementation Research which is useful in that the framework is a validated tool that allows national governments to predict and plan around factors known to be influential for implementation and successfully increasing access to quality essential health services.

- Common challenges include multiple and inconsistent international toolkits and guidance, lack of national capacity for evidence-based healthcare, limited access to essential medicines and technologies, inconsistent national guidelines and limited experience in evaluation methodology, clinical epidemiology and guideline implementation.

\section{INTRODUCTION}

Globally, non-communicable diseases (NCDs) are the leading cause of morbidity and mortality, including in the WHO European region. ${ }^{1}$ In this region, premature mortality is decreasing in every Member State where good data exist, making most Member States on track to meet Sustainable Development Goal 3.4 (a reduction in premature mortality from the four major NCDs by one third by 2030). ${ }^{2}$ The leading causes of premature mortality are cardiovascular diseases (CVDs), a group of conditions which are largely preventable. ${ }^{2}$ Low and lower-middle income countries are 


\begin{tabular}{|c|c|c|c|}
\hline World Bank country income group ${ }^{24}$ & \multicolumn{3}{|c|}{ European epidemiological subregion } \\
\hline High-income economy & $\begin{array}{l}\text { Andorra } \\
\text { Austria } \\
\text { Belgium } \\
\text { Croatia } \\
\text { Cyprus } \\
\text { Czechia } \\
\text { Denmark } \\
\text { Finland } \\
\text { France } \\
\text { Germany } \\
\text { Greece } \\
\text { Iceland } \\
\text { Ireland } \\
\text { Israel } \\
\text { Italy } \\
\text { Luxembourg } \\
\text { Malta } \\
\text { Monaco } \\
\text { Netherlands } \\
\text { Norway } \\
\text { Portugal } \\
\text { San Marino } \\
\text { Slovenia } \\
\text { Spain } \\
\text { Sweden } \\
\text { Northern Ireland }\end{array}$ & $\begin{array}{l}\text { Poland } \\
\text { Slovakia }\end{array}$ & $\begin{array}{l}\text { Estonia } \\
\text { Hungary } \\
\text { Latvia } \\
\text { Lithuania }\end{array}$ \\
\hline Lower-middle-income economy & & $\begin{array}{l}\text { Georgia } \\
\text { Kyrgyzstan }\end{array}$ & $\begin{array}{l}\text { Republic of Moldova } \\
\text { Ukraine }\end{array}$ \\
\hline Low-income economy & & - Tajikistan & \\
\hline
\end{tabular}

disproportionately affected by NCDs and therefore represent an important target for public health intervention. ${ }^{3}$

The WHO European region is a highly diverse group of Member States, ranging from Western Europe (eg, Portugal) to the Eastern Parts of Central Asia (eg, Tajikistan), including the Russian Federation (table 1). Eastern European and Central Asian countries are on average one to two generations behind the rest of the European Region with respect to avoidable NCD mortality, and the main source of premature mortality from NCDs is CVD. ${ }^{2}$ This is attributed to excess male CVD mortality in the East, largely because of high rates of smoking and alcohol use, non-engagement with health services and gender norms that discourage engagement with healthcare. ${ }^{5}$ Furthermore, while average blood pressure has decreased significantly in many regions of the world, Member States in Central Asian and Eastern Europe have not realised these gains and average blood pressure in these jurisdictions remains among the highest in the world. ${ }^{6}$

The Member States with the greatest CVD burden are also some of the lowest resource jurisdictions in the WHO European region. ${ }^{2}$ For this reason, a pragmatic 
approach to implementation focusing on the evidencebased use of resources is essential to maximise the probability of improving national health outcomes within limited resources. Many evidence-based interventions for the prevention and management of CVD are also costeffective $(<$ US $\$ 100$ per DALY averted). These include both clinical interventions (eg, drug therapy for primary prevention for those at high CVD risk, including diabetes and secondary prevention) and policy interventions (eg, increased taxation of alcohol and tobacco, elimination of secondhand smoke exposure, front-of-pack salt labelling). ${ }^{7}$ Herein, we focus more on the implementation of clinical interventions, but it should be noted that a sustainable and effective health system response includes both clinical and policy-level change, for which there are evidenced-based, cost-effective options for low resource settings. $^{7}$

While primary healthcare (PHC) is the cornerstone of achieving universal health coverage and provides better outcomes at lower cost for NCDs, many former Soviet republics have underdeveloped primary and public health systems which are specialist driven and struggle to train and retain PHC physicians. ${ }^{89}$ This is in part because historically, soviet PHC services concentrated on dealing with infectious diseases, antenatal care and lacked longitudinal care for patients with chronic conditions. Soviet PHC in rural areas was provided by a team consisting of a nurse, midwife and feldsher (physician's assistant) and in urban areas, narrow specialists provided primary care in 'polyclinics'. ${ }^{9}$ Following independence, former Soviet Union States have deviated from this model to varying degrees, some choosing to develop specialty training programmes for family medicine (eg, Moldova) which has bolstered PHC. $^{9}$

It is within this context of disease burden and nascent PHC that the need for technical support from the WHO Regional Office for Europe for the implementation of essential CVD/NCD interventions by former Soviet republics became more urgent. In our capacity providing technical support to Member States under the auspices of the WHO, herein we synthesise the key learnings from working with national governments across the European region and share these learnings as a resource for public health professionals to consider when implementing quality essential CVD risk interventions.

\section{A PRACTICAL APPROACH FOR LOW-RESOURCE SETTINGS IN EASTERN EUROPE AND CENTRAL ASIA}

The work and progress of the WHO European Region has provided insight into the unique considerations when implementing essential interventions for CVD risk management in PHC. These considerations are drawn from Member States at various stages of implementation, with varying interpretations of international guidance, and in diverse health systems. ${ }^{10-12}$ Still, through such a breadth of contexts, we have identified six key lessons for future jurisdictions to consider. We map these to the
Consolidated Framework for Implementation Research (CFIR) and highlight key learnings and challenges specific to the region (tables 2 and 3 ) ${ }^{13}$ Case box 1 shows examples of key lessons in action.

\section{Lesson One: Prioritise non-communicable diseases for public health intervention using local data}

Despite international and regional targets for meaningful reductions in premature NCD morbidity and mortality, public health interventions need to be prioritised based on local evidence and distributions of disease burden. ${ }^{14}$ The WHO STEPwise Approach to Noncommunicable Disease Risk Factor Surveillance (WHO STEPS) is a standardised, freely available methodology which enumerates the burden of disease and risk factors in a population. ${ }^{15}$ This information can be used to prioritise specific conditions (eg, CVD) and risk factors (eg, raised blood pressure), build a case for public health intervention and establish a baseline to monitor trends over time. In our experience, the use of nation-specific epidemiological data can improve the implementation climate, build a tension for change and increase the relative priority of NCDs for public health intervention (table 3). ${ }^{13}$ Additionally, collection of these data also allow for meta-epidemiological comparisons between populations, allowing health systems to compare their performance to other populations and systems.

\section{Lesson Two: Identify and map appropriate existing national and international resources}

While there are many freely available resources for implementing essential NCD interventions in PHC (see examples in table 2), these resources were developed to be broadly generalisable to health systems. As such, no single resource is sufficient nor appropriate for direct implementation. Furthermore, given that many health systems are under-resourced, it is wise to use pre-exiting materials when possible. We therefore recommend a process of deconstructing and combining the best components of multiple existing resources into a 'draft intervention package'. When mapping the components of existing resources, several aspects known to influence implementation should be examined. These include the intervention source (perception of whether the intervention is externally or internally developed), the evidence strength and quality (both literal and perceived), relative advantage compared with an alternate intervention, adaptability (the degree to which the intervention can be adapted), the ability to test the intervention, complexity, cost and compatibility with the medical culture (table 3 ). ${ }^{13}$

\section{Lesson Three: Engage key stakeholders from inception to mainstreaming}

Many Member States in the WHO European Region have relatively underdeveloped PHC systems and nascent family medicine training programmes. ${ }^{16}$ Because of this, there is a risk of under-engagement with PHC workers 
Table 2 Summary of key lessons, examples and common challenges

\begin{tabular}{|c|c|c|c|}
\hline Key lesson & Summary & Example & Common challenges \\
\hline $\begin{array}{l}\text { 1. Prioritise NCDs } \\
\text { for public health } \\
\text { intervention using local } \\
\text { data }\end{array}$ & $\begin{array}{l}\text { Use local epidemiological } \\
\text { data to build a case for } \\
\text { public health intervention } \\
\text { and target efforts }\end{array}$ & $\begin{array}{l}\text { 1. Completion of STEPS survey }{ }^{15}-\mathrm{eg} \text {, } \\
\text { Republic of Moldova STEPS }{ }^{29} 30 \\
\text { 2. Identification of key target } \\
\text { populations (eg, men) } \\
\text { 3. Building NCD investment cases }{ }^{31} 32 \\
\text { 4. Assessment of the baseline situation } \\
\text { of NCD burden and performance } \\
\text { of healthcare using the NCD Global } \\
\text { Monitoring Framework Indicators }\end{array}$ & $\begin{array}{l}\text { 1. Competing needs from multiple } \\
\text { disease burdens } \\
\text { 2. Technical capacity to conduct and } \\
\text { interpret epidemiological studies and } \\
\text { in analysis/interpretation of routine } \\
\text { data } \\
\text { 3. Underdeveloped health information } \\
\text { systems }\end{array}$ \\
\hline
\end{tabular}

2. Identify and map Deconstruct and combine 1. WHO PEN ${ }^{34}$

existing national and the best components international resources of multiple existing resources into a draft intervention

1. Existence of multiple initiatives, resources and guidelines make it difficult to choose one

2. Lack of consensus among existing resources

3. Inappropriate content for local contexts

4. Over-reliance on expert opinion

1. Conflicts of interest

2. Human resource capacity

3. Allocation of working time for development

4. Physician perception of nonphysician health workers (eg, nurses)

5. Availability of 'expert' patients

6. Physician/non-physician and expertperson/lay-person power dynamics

7. Specialist/generalist physician power dynamics

4. Tailor intervention to Reconcile and adapt local health system draft intervention with existing national clinical guidelines, availability of resources and local contextual wisdom
1. Access to essential medicines

2. Access to laboratory and diagnostic tests

3. Appropriate and aligned health financing

4. Scope of practice of family doctors, nurses and narrow specialists

1. Reluctance and/or lack of power and/or capacity to simplify existing national guidelines to be more practical

2. Reluctance of task shifting care from specialists to primary care doctors and from doctors to nurses/nondoctors

\begin{tabular}{|c|c|c|c|}
\hline $\begin{array}{l}\text { 5. Generate } \\
\text { local evidence of } \\
\text { effectiveness }\end{array}$ & $\begin{array}{l}\text { Demonstrate } \\
\text { effectiveness locally } \\
\text { through pragmatic, high } \\
\text { quality, clinical trials }\end{array}$ & $\begin{array}{l}\text { 1. Pragmatic clinical trials, mixed } \\
\text { methods evaluations, }{ }^{1920} \text { open- } \\
\text { science resources including } \\
\text { whoishRisk }{ }^{17} \text { and CFIR }{ }^{13} \\
\text { 2. European Health Examination Survey } \\
\text { guidelines }^{40}\end{array}$ & $\begin{array}{l}\text { 1. Eagerness to change and optimism } \\
\text { about intervention effects } \\
\text { 2. Lack of local (ie, national) trial } \\
\text { methodologists, data analysts, } \\
\text { especially for qualitative research } \\
\text { 3. Lack of resources/capacity for } \\
\text { data collection, analysis and } \\
\text { interpretation }\end{array}$ \\
\hline $\begin{array}{l}\text { 6. Ensure continuous } \\
\text { quality improvement } \\
\text { while before, } \\
\text { during and after } \\
\text { mainstreaming }\end{array}$ & $\begin{array}{l}\text { If effective and } \\
\text { acceptable, } \\
\text { mainstreaming into the } \\
\text { health system while } \\
\text { balancing quality with } \\
\text { scale }\end{array}$ & $\begin{array}{l}\text { 1. Engagement of local health leaders } \\
\text { and academics throughout design, } \\
\text { testing and scale-up }{ }^{41} \\
\text { 2. Integration with medical education } \\
\text { and continuous medical education }{ }^{42} \\
\text { 3. Introducing quality circles and clinical } \\
\text { audit to medical culture }\end{array}$ & $\begin{array}{l}\text { 1. Funding } \\
\text { 2. Oversight, quality assurance } \\
\text { 3. Punitive culture } \\
\text { 4. Excessive workload in primary } \\
\text { healthcare } \\
\text { 5. Limited health informatics } \\
\text { infrastructure for audit and feedback } \\
\text { 6. Unspecified leadership and roles }\end{array}$ \\
\hline
\end{tabular}

NCD, non-communicable disease.

in the development of PHC, in what is often largely a specialist-driven climate. Recognising frontline $\mathrm{PHC}$ workers (including physicians, nurses, managers and allied health professionals) as key stakeholders can help assess the basic assumptions of the programme, the need and capacity for change, the perceived relative priority of the programme, advice on reallocation of resources and clinical tasks and identify leaders to aid in championing change (table 3). ${ }^{13}$ Furthermore, recognising patients and the public as stakeholders can help align programme goals and structure so as to increase the chance of implementation success. ${ }^{13}$ 


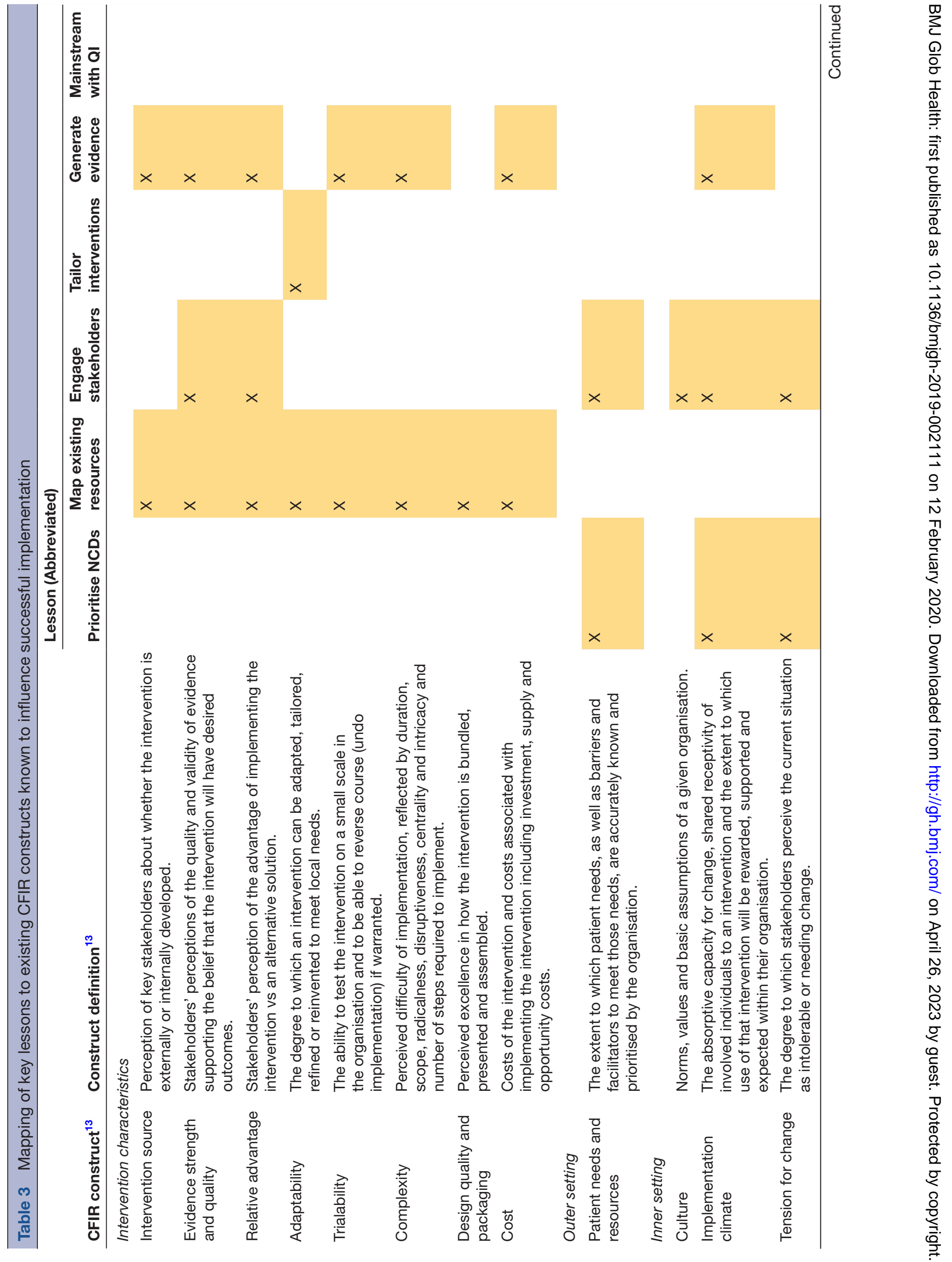




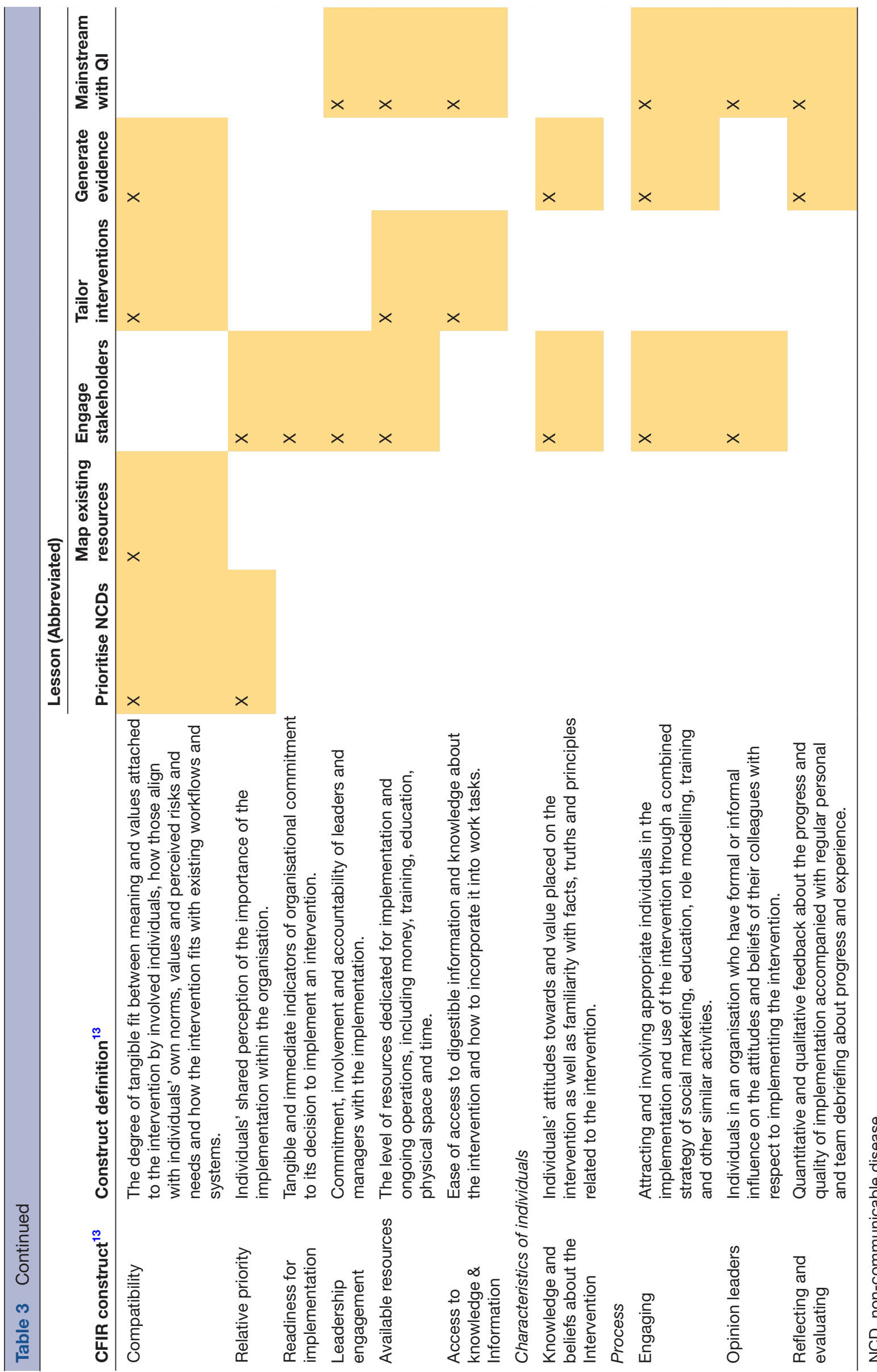


Box 1 Key lessons in action in the Republic of Moldova, Ukraine, Uzbekistan and Tajkistan

The following are examples of key lessons in action from across Central Asia and Eastern Europe, chosen to illustrate the breadth and scale of improving access to quality essential health services.

\section{Generating evidence for decision making in the Republic of Moldova}

In the Republic of Moldova, a year-long cluster randomised pilot implementation and mixed methods evaluation was designed in order to optimise essential interventions for NCDs in PHC and to determine the feasibility of measuring their effectiveness using routine clinical data. This was part of a project cofunded by WHO and the Swiss Agency for Development and Cooperation (SDC) and was done with a view towards national scale-up with systems for monitoring, evaluation and continuous quality improvement. This approach also aimed to build national capacity in research methodology, monitoring and evaluation and to pioneer methodology and research instruments which could be used in other settings. ${ }^{25}$

\section{Developing appropriate and effective trainings for family doctors in Ukraine}

As part of a project cofunded by WHO and SDC, a country-contextspecific package of Essential Training on the Integrated Management of Hypertension and Diabetes was developed with the support of WHO during 2016, drawing on existing national materials as international guidance. This was piloted and evaluated, then used for a cascaded training of trainers. By March 2018, 8000 PHC workers in seven pilot regions had completed the training package and received simple clinical decision support tools such as desktop laminated cards with risk prediction tools. The impact of the training on clinical practice will be assessed using mixed methods. ${ }^{26}$

\section{Integrating with undergraduate medical education in Tajikistan}

In Tajikistan, national clinical guidelines were adapted to include the WHO/ISH risk prediction chart and simple clinical protocols were developed based on WHO PEN. With the cofunding and support of WHO, a national team in Tajikistan then developed a 2-day training for family doctors and nurses in using the tools for CVD risk assessment and management, including control of diabetes and hypertension. This training in the use of protocols and risk prediction charts has also been introduced into the university undergraduate curricula and postgraduate studies. $^{27}$

\section{Combining implementation with continuous quality improvement in Uzbekistan}

As part of a WHO/World Bank-supported project, primary care facilities in two regions in Uzbekistan adapted and implemented the WHO PEN package of clinical protocols, supported by community-level interventions to facilitate change in risk factor behaviours. Over 12 months, the intervention led to greater coverage of the target population and improved detection and control of cardiovascular risk factors, as well as increasing the engagement of men in NCD prevention. ${ }^{28}$ Both family doctors and nurses received training and support leading to better organisation of care, increased task-sharing between doctors and nurses and enhanced the role of nurses in PHC. The intervention included regular monitoring of key performance indicators through audits of case records, observed clinical practice and interviews with patients and practitioners on a quarterly basis, with timely feedback and clinical supervision.

NCDs, non-communicable diseases; PHC, primary healthcare.

\section{Lesson Four: Tailor intervention to local health system}

Before piloting to generate local evidence of effectiveness (Lesson Five), the draft intervention using existing resources should be tailored to suit the local health system, with a specific view towards sustainability. While there may be a bias to promote international best practice, this desire needs to be balanced with pragmatism to ensure that if effective, it can actually be implemented in PHC. Key considerations include the access and availability of medicines included in newly developed guidelines, the training and skills of PHC workers, referral networks to secondary and tertiary care, the availability of laboratory testing and the capacity of health informatics to register, record, remind and recall patients. It is important to also examine the resources available to conduct training of healthcare workers, the availability of clinical decision support tools (such as printed one-page clinical algorithms), the capacity to perform patient education with relevant printed health education materials and how tasks can be shared between physician and non-physician health workers (table 3$){ }^{13}$

\section{Lesson Five: Generate local evidence of effectiveness}

The generation of local evidence of effectiveness through pragmatic clinical trials is an essential step that helps to identify factors affecting successful implementation, including: intervention source, evidence strength and quality, relative advantage, complexity, cost, implementation climate, compatibility, knowledge and beliefs of the intervention and engagement of health workers and academics through training and capacity building (table 3). ${ }^{13}$ Importantly, gathering local evidence early in health systems development allows for the potential of deadoption if the intervention is not effective, causes harm or is unlikely to be sustainable. Some freely available resources are available to help conduct pragmatic trials, including open-source $\mathrm{R}$ Software for WHO/ ISH risk scores, ${ }^{17}$ the CFIR, ${ }^{13}$ the WHO Framework for Operations and Implementation Research in Health and Disease Control Programs, ${ }^{18}$ published examples of mixed methods evaluations in low-resource settings ${ }^{19}$ and clear methodological guidance on qualitative research. ${ }^{20}$

\section{Lesson Six: Ensure continuous quality improvement while mainstreaming}

If the decision is made to mainstream interventions throughout the PHC system, implementation success is in part built on the ability to provide quantitative and qualitative feedback in a timely and effective way to frontline staff. ${ }^{13}$ Scaling too quickly and without quality improvement infrastructure such as peer-to-peer support, clinical audit training, quality circles, knowledge of plan-dostudy-act cycles, runs the risk of sacrificing quality of care for widespread scale-up.

\section{CONCLUSION}

Achievement of universal healthcare and reduction of premature CVD mortality require functioning PHC 
systems that increase coverage of quality essential health services. Immense effort has gone into developing free, open-source, evidence-based guidelines and public policy packages; however, implementation remains challenging. We therefore hope that by mapping our six key lessons to validated CFIR domains, this will help national governments to predict and plan around factors known to be influential for the improving access to quality essential health services. While Member States in the region are at various stages of implementation, several are currently conducting pragmatic cluster randomised trials to generate local evidence for health policy that will help add to the implementation science evidence base. ${ }^{21} 22$ As this work expands, greater engagement with peer-to-peer sharing of contextual wisdom, sharing of resources and publishing methodology and results and development of regionspecific resources is planned. This includes organising workshops that bring together Member States to share their experiences and build organic communities of practices and to build capacity for implementation research. ${ }^{23}$ By building capacity for implementation research, the hope is that Member States will be better prepared to conduct and communicate their findings in open access journals and share their experiences even beyond their own communities of practice. From these initial workshops with 13 Member States, a specific need has been identified for region-specific resources for training of PHC workers, including the identification of key clinical competencies and a core learning outcome set. Future work includes highlighting the importance and leadership and organisational structures that support implementation, including the allocation of proper resources. This includes how projects can be mainstreamed in a sustainable way without reductions in quality.

Twitter Dylan Collins @DylanRJCollins

Acknowledgements Staff of the WHO Country Offices in Ukraine, Republic of Moldova, Tajikistan, Uzbekistan, national authorities, development partners who contributed to specific projects referred to financially and technically (World Bank, Swiss Government/SDC) and donors (Russian Federation).

Contributors DC, TL and JF conceptualised and wrote the manuscript. All authors agreed on the final version.

Funding The authors have not declared a specific grant for this research from any funding agency in the public, commercial or not-for-profit sectors.

Competing interests None declared.

Patient consent for publication Not required.

Provenance and peer review Not commissioned; externally peer reviewed.

Data availability statement There are no data to share.

Open access This is an open access article distributed in accordance with the Creative Commons Attribution Non Commercial (CC BY-NC 4.0) license, which permits others to distribute, remix, adapt, build upon this work non-commercially, and license their derivative works on different terms, provided the original work is properly cited, appropriate credit is given, any changes made indicated, and the use is non-commercial. See: http://creativecommons.org/licenses/by-nc/4.0/.

Author note JF is a staff member of the World Health Organization. JF alone is responsible for the views expressed in this publication and they do not necessarily represent the views, decisions or policies of the World Health Organization.

ORCID iD

Dylan Collins http://orcid.org/0000-0002-5939-2163

\section{REFERENCES}

1 GBD 2016 Causes of Death Collaborators. Global, regional, and national age-sex specific mortality for 264 causes of death, 19802016: a systematic analysis for the global burden of disease study 2016. Lancet 2017;390:1151-210.

2 Jakab M, Farrington J, Borgermans L, et al. Health systems respond to noncommunicable diseases: time for ambition [Internet]. Copenhagen, 2018. Available: http://www.euro.who.int/_data/ assets/pdf_file/0009/380997/hss-ncd-book-eng.pdf?ua=1

3 Roth GA, Huffman MD, Moran AE, et al. Global and regional patterns in cardiovascular mortality from 1990 to 2013. Circulation 2015;132:1667-78.

4 World Health Organization. European Region [Internet], 2018. Available: http://www.who.int/choice/demography/euro_region/en/ [Accessed 18 Aug 2018].

5 World Health Organization. The health and well-being of men in the WHO European Region: better health through a gender approach. [Internet]. Copenhagen, 2018. Available: http://www.euro.who.int/ data/assets/pdf_file/0007/380716/mhr-report-eng.pdf?ua=1

6 NCD Risk Factor Collaboration (NCD-RisC). Worldwide trends in blood pressure from 1975 to 2015: a pooled analysis of 1479 population-based measurement studies with 19.1 million participants. Lancet 2017;389:37-55.

7 Organization WH. Tackling NCDs: "Best buys" and other recommended interventions for the prevention and control of noncommunicable diseases [Internet], 2017. Available: http://www. who.int/ncds/management/best-buys/en/

8 World Health Organization (WHO). Who Pen conceptual framework

9 European Observatory on Health Systems and Policies. Trends in health systems in the former Soviet countries [Internet], 2014. Available: http://www.euro.who.int/_data/assets/pdf_file/0019/ 261271/Trends-in-health-systems-in-the-former-Soviet-countries.pdf

10 World Health Organization Regional Office for Europe. Workshop on implementation of the Package of essential noncommunicable (PEN) disease interventions for primary health care in the central Asian republics (2015) [Internet]. Copenhagen, 2015. Available: http://www. euro.who.int/_data/assets/pdf_file/0008/335546/PEN-meetingreport-15.pdf

11 World Health Organization Regional Office for Europe. Workshop on implementation of a package of essential noncommunicable (PEN) disease interventions for primary health care in eastern Europe and central Asia (2017) [Internet]. Copenhagen, 2017. Available: http:// www.euro.who.int/_data/assets/pdf_file/0011/355790/PEN-report2017-Finland_ENG.pdf

12 World Health Organization. Workshop on implementation of a package of essential noncommunicable (Pen) disease interventions for primary health care in eastern Europe and central Asia, 2017.

13 CFIR Research Team. The Consolidated Framework for Implementation Research [Internet], 2018. Available: https:// cfirguide.org [Accessed 20 Aug 2018].

14 World Health Organization (WHO). Global action plan for the prevention and control of NCDS 2013-2020, 2013.

15 World Health Organization. STEPwise approach to noncommunicable disease risk factor surveillance (STEPS) [Internet], 2017. Available: http://www.who.int/ncds/surveillance/steps/STEPS_ Manual.pdf

16 European Observatory on Health Systems and Policies. Building primary care in a changing Europe [Internet]. Copenhagen, 2015. Available: http://www.euro.who.int/ data/assets/pdf file/0018/ 271170/BuildingPrimaryCareChangingEurope.pdf?ua $=1$

17 Collins D, Lee J, Bobrovitz N, et al. whoishRisk - an R package to calculate $\mathrm{WHO} / \mathrm{ISH}$ cardiovascular risk scores for all epidemiological subregions of the world. F1000Res 2016;5:2522.

18 World Health Organization. Framework for Operations and Implementation Research in Health and Disease Control Programs [Internet], 2008. Available: http://www.who.int/hiv/pub/operational/ or framework.pdf?ua=1

19 Collins DRJ, Jobanputra K, Frost T, et al. Cardiovascular disease risk and prevention amongst Syrian refugees: mixed methods study of Médecins sans Frontières programme in Jordan. Confl Health 2017;11:14.

20 Gale NK, Heath G, Cameron E, et al. Using the framework method for the analysis of qualitative data in multi-disciplinary health research. BMC Med Res Methodol 2013;13:117.

21 Collins D, Ciobanu A, Laatikainen T, et al. Protocol for the evaluation of a pilot implementation of essential interventions for the prevention of cardiovascular diseases in primary healthcare in the Republic of Moldova. BMJ Open 2019;9:e025705.

22 Collins DRJ, Laatikainen T, Shoismatuloeva M, et al. Evaluation and pilot implementation of essential interventions for the management of hypertension and prevention of cardiovascular diseases in primary 
health care in the Republic of Tajikistan [version 1; peer review: awaiting peer review]. F1000. Research 2019;8.

23 WHO. Workshop on implementing package of essential NCD interventions (PEN) for primary health care in eastern Europe and central Asia [Internet]. Available: http://www.euro.who.int/en/mediacentre/events/events/2017/03/workshop-on-implementing-packageof-essential-ncd-interventions-pen-for-primary-health-care-ineastern-europe-and-central-asia [Accessed 9 Jan 2020].

24 The World Bank. World Bank Country and Lending Groups [Internet], 2019. Available: https://datahelpdesk.worldbank.org/ knowledgebase/articles/906519-world-bank-country-and-lendinggroups [Accessed 6 Jan 2019].

25 Who country office in the Republic of Moldova. tackling noncommunicable diseases in the Republic of Moldova. Copenhagen 2018.

26 WHO Country Office of Ukraine. Tackling noncommunicable diseases in Ukraine [Internet], 2018. Available: http://www.euro.who. int/ data/assets/pdf file/0004/385078/ukr-leaflet-hr-eng.pdf

27 World Health Organization Regional Office for Europe. Workshop on implementation of a package of essential noncommunicable (PEN) disease interventions for primary health care in eastern Europe and central Asia [Internet]. Copenhagen, 2017. Available: http://www. euro.who.int/ data/assets/pdf file/0011/355790/PEN-report-2017Finland_ENG.pdf?ua $=1$

28 Sadirova M, Aniyozova D, Farrington J, et al. Improving cardiovascular risk in Uzbekistan: implementing a package of essential interventions to prevent and control noncommunicable diseases successfully involved nurses and found missing men, 2018

29 World Health Organization (WHO). Prevalence of Noncommunicable Disease Risk Factors in the Republic of Moldova (STEPS) [Internet], 2014. Available: http://www.who.int/ncds/surveillance/steps/ Moldova_2013_STEPS_Report.pdf

30 World Health Organization. STEPS Country Reports [Internet], 2018. Available: http://www.who.int/ncds/surveillance/steps/reports/en/ [Accessed 30 Sep 2018].
31 World Health Organization. Prevention and control of noncommunicable diseases in Belarus: the case for investment, 2018.

32 World Health Organization. Prevention and control of noncommunicable diseases in Kyrgyzstan: the case for investment, 2017.

33 World Health Organization. NCD Global Monitoring Framework [Internet], 2011. Available: https://www.who.int/nmh/global monitoring_framework/2013-11-06-who-dc-c268-whp-gap-ncdstechdoc-def3.pdf?ua $=1$

34 World Health Organization (WHO). Package of Essential Noncommunicable (PEN) disease interventions for primary health care in low-resource settings [Internet], 2013. Available: http://www. who.int/ncds/management/pen_tools/en/

35 European Society of Cardiology. Score charts, 2012.

36 World Health Organizatin. Hearts technical package. Geneva, 2018

37 Resolve to Save Lives [Internet]. Available: https://www. resolvetosavelives.org [Accessed 30 Sep 2018].

38 World Health Organization. Toolkit for deliverying the $5 A$ 's and $5 R$ 's brief tobacco interventions in primary care, 2014

39 World Health Organization. WHO alcohol brief intervetion training manual primary care [Internet], 2017. Available: http://www.euro. who.int/_data/assets/pdf_file/0006/351294/Alcohol-trainingmanual-final-edit-LSJB-290917-new-cover.pdf

40 National Institute for Health and Welfare. Guidelines for health examination surveys, 2010.

41 Leviton LC, Melichar L. Balancing stakeholder needs in the evaluation of healthcare quality improvement. BMJ Qual Saf 2016;25:803-7.

42 Tor E, Steketee C, Mak D. Clinical audit project in undergraduate medical education curriculum: an assessment validation study. Int $J$ Med Educ 2016;7:309-19.

43 Benjamin A. Audit: how to do it in practice. BMJ 2008;336:1241-5. 